\title{
Khảo sát nhận thức, thái độ và xác định một số yếu tố liên quan ở bệnh nhân người dân tộc thiểu số bị tăng huyết áp
}

\author{
Nguyễn Văn Dũng*, Chu Vũ Sơn, Trần Viết Hòa
}

\section{TÓM TẮT}

Mục tiêu: khảo sát nhận thức, thái độ và xác định một số yếu tố liên quan ở bệnh nhân người dân tộc thiểu số bị Tăng huyết áp tới khám và điều trị tại Bệnh viện Quân y 6.

Phương pháp: Nghiên cứu mô tả, cắt ngang 97 bệnh nhân người dân tộc thiểu số được chẩn đoán Tăng huyết áp bằng phỏng vấn, đo đạc các chỉ số nhân trắc theo bộ câu hỏi điều tra soạn sẵn.

Kết quả: nhận thức, thái độ của bệnh nhân về THA: 19.59\% chưa nghe về bệnh THA; kiểm tra HA định kỳ $7.21 \%$, khi có triệu chứng $24.74 \%$, không kiểm tra $68.04 \%$; đối tượng biết về tai biến do THA nhưng không đầy đủ chiếm 26.81\%; HA tăng tỷ lệ thuận với $\mathrm{BMI}, \mathrm{p}<0.01$; Vòng bụng trung bình nữ cao hơn nam $(89.83 \pm$ $5.50 \mathrm{~cm}$ so với $87.27 \pm 5.59 \mathrm{~cm}), \mathrm{p}<0.05$, có mối tương quan thuận, mức độ vừa với $\mathrm{HA}\left(\mathrm{r}_{\mathrm{HATTr}}=\right.$ $\left.0.44, \mathrm{r}_{\mathrm{HATT}}=0.56\right)$.

Kết luận: Nhận thức, thái độ của người dân tộc thiểu số về THA còn rất hạn chế so với vùng đồng bằng, thành phố. Vòng bụng của người dân tộc có xu hướng cao hơn người kinh. THA có mối tương quan thuận với vòng bụng và chỉ số BMI.

*Tù khóa: Tăng huyết áp, Người dân tộc thiểu số, Bệnh viện Quân y 6.

\section{ABSTRACT \\ SURVEY ON AWARENESS, ATTITUDE AND IDENTIFY SOME RELATED FACTORS IN ETHNIC MINORITIES PATIENNTS WITH HYPERTENSION}

Background: to study awareness, attitude and determine some associated factors in hypertensive patients from ethnic minority who come to Military Hospital 6 for examination and treatment.

Methods: Descriptive, cross-sectional study of 97 ethnic minority patients diagnosed with hypertension by interview, measurement of anthropometric indicators according to a set of survey questionnaires.

Results: Awareness, attitude of patients about hypertension: $19.59 \%$ have not heard about hypertension; Periodical checking BP 7.21\%, when having symptoms $24.74 \%$, not checking $68.04 \%$; subjects who not fully knew about complications with regard to hypertension accounted for $26.81 \%$; BP increased proportionally with BMI, $\mathrm{p}<0.01$; The average waist circumference of women was higher than that of men $(89.83 \pm 5.50 \mathrm{~cm}$ compared with $87.27 \pm 5.59 \mathrm{~cm}), \mathrm{p}<0.05$, there was a positive, moderate correlation with BP (rHATTr $=0.44$, $\operatorname{rHATT}=0.56)$.

Bệnh viện Quân y 6

*Tác giả liên hệ: Nguyễn Văn Dũng

Email: haclights@gmail.com - DT: 0399528439

Ngày nhận bài: 9/11/2021 Ngày Cho Phép Đăng: 28/12/2021 
Conclusions: Awareness and attitudes of ethnic minorities about hypertension are still limited compared to plains and cities. The waist circumference of ethnic people tends to be higher than that of Kinh people. Hypertension has a positive correlation with waist circumference and BMI.

*Keywords: Hypertension, Ethnic minorities, Military Hospital 6.

\section{I. ĐẠTT VÁN ĐỀ:}

Trong bệnh lý tim mạch, tăng huyết áp (THA) là bệnh lý thường gặp, đã ảnh hưởng lên khoảng hơn 1 tỷ người trên thế giới. Do vậy, gánh nặng bệnh tật và tử vong do tăng huyết áp và các bệnh mạn tính không lây là một trong các vấn đề sức khỏe cộng đồng cấp bách nhất hiện nay. Theo Tổ chức Y tế thế giới năm 1978, trên thế giới tỷ lệ mắc bệnh THA chiếm khoảng $10 \%$ - 15\% dân số và ước tính đến 2025 là $29 \%$ với sự gia tăng lớn ở các nước thu nhập thấp và trung bình [1]. Theo Tổng điều tra toàn quốc về yếu tố nguy cơ bệnh không lây nhiễm ở Việt Nam năm 2015, có $18,9 \%$ người trưởng thành trong độ tuổi 18-69 tuổi bị tăng huyết áp, trong đó có $23,1 \%$ nam giới và $14,9 \%$ nữ giới [2]. Mối tương quan giữa THA và các biến chứng như nhồi máu cơ tim, suy tim, đột quỵ và suy thận là liên tục và có tính độc lập với các nguy cơ khác.

Trong nước, có rất nhiều đề tài nghiên cứu về thực trạng bệnh THA và các yếu tố liên quan đã được công bố nhưng các đề tài chủ yếu được thực hiện tại các thành phố lớn cũng như tại các xã, tỉnh miền đồng bằng, chưa có nhiều nghiên cứu tại các tỉnh miền núi với đối tượng là đồng bào các dân tộc thiểu số với chế độ sinh hoạt, ăn uống có nhiều đặc điểm riêng. Sơn La là tỉnh miền núi Tây Bắc Việt Nam, tỉnh có diện tích đứng thứ 3 trong số 63 tỉnh thành phố nhưng dân số chỉ khoảng 1,2 triệu người, điều kiện kinh tếxã hội còn gặp rất nhiều khó khăn, đây là nơi sinh sống của 12 dân tộc thiểu số anh em. Với tính chất đó, chúng tôi tiến hành thực hiện đề tài nhằm khảo sát nhận thức, thái độ và xác định một số yếu tố liên quan ở bệnh nhân người dân tộc thiểu số bị Tăng huyết áp.

\section{II. ĐỐI TƯợnG VÀ PHƯỚNG PHÁP NGHIÊN CÚU:}

\section{1. Đối tượng nhiên cứu}

- 97 BN người dân tộc thiểu số được chẩn đoán THA theo hội Tim mạch học Việt Nam tới khám và điều trị tại Bệnh viện Quân y 6 từ tháng 4/2019 đến 10/2019.

- Loại trừ các bệnh nhân không đồng ý tham gia nghiên cứu.

\subsection{Phương pháp nghiên cứu}

- Nghiên cứu tiến cứu, mô tả, cắt ngang, cỡ mẫu thuận tiện.

- BN được hỏi, khám bệnh, đo các chỉ số nhân trắc rồi điền vào bộ câu hỏi điều tra đã soạn sẵn theo hướng dẫn của WHO STEP.

Nội dung nghiên cứu gồm: thông tin chung về đối tượng nghiên cứu, mức độ hiểu biết của người dân về bệnh tăng huyết áp, tiền sử về bệnh tăng huyết áp, các hành vi sức khỏe liên quan đến bệnh tăng huyết áp.

* Cách đo HA, vòng bụng:

- Đo huyết áp tại phòng khám (huyết áp lâm sàng): Sư dụng huyết áp kế thưy ngân, đo $H A$ theo phuong pháp Korotkoff.

- Cách đo vòng bụng (theo hướng dẫn của hội Tim mạch học Việt Nam): Tìm điểm cuối của xương sườn và điểm đầu của hông. Thở ra tự nhiên, dùng thước dây quấn quanh bụng giữa hai điểm đã tìm thấy bên trên. Chú ý thước đo phải 
nằm song song với mặt sàn và ôm khít xung quanh thân trên và không hằn sâu vào $\mathrm{da}$, không bị xoắn vặn.

+ Xử lý số liệu theo thuật toán thống kê bằng phần mềm SPSS 20.0.

III. KẾT QUẢ NGHIÊN CÚU VÀ BÀN LUẬN:

Tuổi trung bình $58.74 \pm 13.40$ tuổi, nam
45.36\% và nữ 54.64\%. Dân tộc: Thái 95.87\%, Mường $2.07 \%$, La $\mathrm{Ha} 1.03 \%$, Dao $1.03 \%$. Trình độ học vấn: $49.48 \%$ mù chữ, $41.24 \%$ cấp 1-2-3, cao đẳng đại học 9.28\%. Nghề nghiệp: $80.41 \%$ nông dân, cán bộ hưu trí $16.49 \%$. Tình trạng kinh tế: $20.62 \%$ khá-giàu, $54.64 \%$ trung bình, nghèo $24.74 \%$.

\section{Nhận thức chung của bệnh nhân về bệnh Tăng huyết áp}

Bảng 1. Đối tượng đã từng nghe về bệnh THA

\begin{tabular}{|l|l|c|c|}
\hline \multicolumn{2}{|l|}{ Đối tượng } & Số lượng (n) & Tỷ lệ (\%) \\
\hline Đã nghe & Biết bị THA & 47 & 48.45 \\
\hline & Chưa biết & 31 & 31.96 \\
\hline Chưa nghe & & 19 & 19.59 \\
\hline Tổng & 97 & 100 \\
\hline
\end{tabular}

Trong 97 bệnh nhân tham gia nghiên cứu, đa số đã từng nghe về bệnh THA nhưng số đối tượng chưa từng nghe về bệnh THA khá nhiều, chiếm 19.59\%. Trong số đối tượng đã nghe về THA thì có tới 31/97 (31.96\%) đối tượng chưa biết mình bị THA. Điều này hoàn toàn phù hợp với điều kiện kinh tế cũng như trình độ dân trí của người dân tộc sống trên địa bàn Tây Bắc với tỷ lệ mù chữ lên tới 49.48\% và $24.74 \%$ kinh tế nghèo đói, ít có điều kiện quan tâm chăm sóc sức khỏe định kỳ.

Bảng 2. Tần xuất kiểm tra $\mathrm{HA}$

\begin{tabular}{|l|l|r|r|}
\hline \multicolumn{1}{|l|}{ Đối tượng } & Số lượng (n) & Tỷ lệ (\%) \\
\hline Định kỳ & Tuần 1 lần & 2 & 2.06 \\
\hline & Tháng 1 lần & 5 & 5.15 \\
\hline Khi có triệu chứng & & 24 & 24.74 \\
\hline Không kiểm tra & 66 & 68.04 \\
\hline Tổng & 97 & 100 \\
\hline
\end{tabular}

Trong nghiên cứu, các đối tượng đã biết mình bị THA chỉ có 7/47 (14.89\%) bệnh nhân kiểm tra HA định kì, đây đều là đối tượng cán bộ công chức và quân nhân; $68.04 \%$ số bệnh nhân đã bị THA nhưng không kiểm tra HA cũng như không dùng thuốc HA tại nhà. Qua đây ta thấy mặc dù là các đối tượng được chẩn đoán THA theo tiêu chuẩn nhưng do điều kiện sống ở những vùng kinh tế khó khăn, trình độ dân trí thấp kém, tỷ lệ mù chữ cao, xa trung tâm y tế nên số bệnh nhân chưa bao giờ nghe cũng như bệnh nhân người dân tộc bị THA chưa được chẩn đoán còn cao. 
Bảng 3. Phân bố đối tượng biết về tai biến do THA

\begin{tabular}{|l|c|c|}
\hline Tai biến do THA & Số lượng (n) & Tỷ lệ (\%) \\
\hline TBMMN & 12 & 12.37 \\
\hline Tim & 5 & 5.16 \\
\hline Thận & 0 & 0 \\
\hline Mắt & 0 & 0 \\
\hline Tử vong & 9 & 9.28 \\
\hline Không biết & 71 & 73.19 \\
\hline Tổng & 97 & 100 \\
\hline
\end{tabular}

Hiểu biết về các biến chứng do THA gây ra thì $100 \%$ hiểu biết không đầy đủ, trong đó chỉ có 12/97 bệnh nhân biết về biến chứng não, $5 / 97(5.16 \%) \mathrm{BN}$ biết về biến chứng tim mạch và $9 / 97$ $(9.28 \%)$ BN biết THA có thể gây tử vong còn lại có tới $73.19 \%$ đối tượng không biết gì về biến chứng do THA gây ra. Các biến chứng thận hay mắt các bệnh nhân đều không biết là 1 trong các biến chứng do THA gây nên. Điều này cũng được giải thích là do trình độ dân trí của người bệnh rất thấp.

\section{Bảng 4. Phân bố đối tượng biết cách phòng tránh THA}

\begin{tabular}{|c|c|c|}
\hline Phương pháp & Số lượng (n) & Tỷ lệ (\%) \\
\hline Rèn luyện thể lực & 3 & 3.09 \\
\hline Không uống rượu bia, thuốc lá & 28 & 28.87 \\
\hline Hạn chế ăn mặn & 8 & 8.25 \\
\hline Hạn chế ăn đồ chiên rán & 2 & 2.06 \\
\hline Tránh stress & 0 & 0 \\
\hline Chống béo phì & 4 & 4.12 \\
\hline Không biết & 52 & 53.61 \\
\hline Tổng & 97 & 100 \\
\hline
\end{tabular}

Theo kết quản nghiên cứu trong tổng số 97 bệnh nhân tham gia nghiên cứu có tới 53.61\% đối tượng không biết các biện pháp phòng tránh THA, còn lại $46.39 \%$ biết một trong các biện pháp phòng tránh THA; chỉ có $2 / 97$ đối tượng hiểu biết đầy đủ các biện pháp cơ bản phòng tránh THA. Trong $46.39 \%$ đối tượng trên thì có $39.18 \%$ BN biết yếu tố nguy cơ cao nhất là uống rượu bia, hút thuốc lá; còn lại một ít các đối tượng biết các phương pháp khác như rèn luyện thể lực, hạn chế ăn mặn, hạn chế ăn đồ chiên rán, chống stress. So với một số nghiên cứu dịch tễ học THA và các yếu tố liên quan ở các địa bàn cao nguyên, đồng bằng, ven biển và thành thị trước đây thì trình độ dân trí cũng như nhận thức của người dân tộc Sơn La về THA còn rất hạn chế $[3,4,5]$. 


\section{Tình trạng Tăng huyết áp và các mối liên quan}

Bảng 5. Chỉ số trung bình của HATTr, HATT theo giới

\begin{tabular}{|l|c|c|c|}
\hline Giới & Số lượng $(\mathbf{n})$ & $\begin{array}{c}\text { HATTr }(\mathbf{m m H g}) \\
\overline{\mathbf{x}} \pm \mathbf{S D})\end{array}$ & $\begin{array}{c}\text { HATT (mmHg) } \\
(\overline{\mathbf{X}} \pm \mathbf{S D})\end{array}$ \\
\hline Nam & 44 & $97.93+8.35$ & $160.91+9.57$ \\
\hline Nữ & 53 & $103.40+11.43$ & $169.42+15.66$ \\
\hline Chung & 97 & $100.92 \pm 10.46$ & $165.56 \pm 13.86$ \\
\hline $\mathrm{p}$ & & 0.01 & 0.002 \\
\hline
\end{tabular}

Trong nghiên cứu, độ tuổi bị nhiều nhất là 41-60 tuổi chiếm $>50 \%$ số đối tượng, sự khác biệt HATT, HATTr trung bình giữa các nhóm tuổi không có ý nghĩa thống kê ( $\mathrm{p}>0.05)$. Giá trị HATT và HATTr trung bình là $165.56 \pm 13.86 \mathrm{mmHg}$ và $100.92 \pm 10.46 \mathrm{mmHg}$. So sánh về giới thì HATT, HATTr trung bình của giới nữ cao hơn giới nam, lần lượt là $169.42+15.66 \mathrm{mmHg}$ so với $160.91+$ $9.57 \mathrm{mmHg}$ và $103.40+11.43 \mathrm{mmHg}$ so với $97.93+8.35 \mathrm{mmHg}$, sự khác biệt này có ý nghĩa thống kê với $\mathrm{p}<0.05$ (Bảng ). So với nhiều kết quả điều tra dịch tễ học THA trước đây HATT và HATTr trung bình của nam giới luôn cao hơn của nữ giới thì kết quả trong nghiên cứu này có sự khác biệt có ý nghĩa [5]. Điều này có thể phản ánh phần nào cơ cấu bệnh nhân người dân tộc tại Sơn La bị THA ở nữ giới bị nhiều hơn nam giới, nó cũng phần nào giải thích mối liên quan trực tiếp giữa THA với tỷ lệ béo phì, số đo vòng bụng lớn ở phụ nữ và chế độ ăn của người dân tộc vùng Tây Bắc có phần khác biệt so với người thành phố, đồng bằng. Theo phong tục, tập quán người dân tộc hay ăn đồ nếp, thịt khô, đồ muối và chấm muối nhiều ở các món ăn. Do vậy tỷ lệ béo bụng, thừa cân và THA ở nữ giới cao hơn nam giới.

\section{Bảng 6. Mối liên quan giữa THA theo BMI}

\begin{tabular}{|l|c|c|c|}
\hline Nhóm BMI & Số lượng $(\mathbf{n})$ & $\begin{array}{c}\text { HATTr }(\mathbf{m m H g}) \\
(\overline{\mathbf{x}} \pm \mathbf{S D})\end{array}$ & $\begin{array}{c}\text { HATT (mmHg) } \\
(\overline{\mathbf{x}} \pm \mathbf{S D})\end{array}$ \\
\hline $\begin{array}{l}\text { Thiếu cân } \\
(\text { BMI }<18.5)\end{array}$ & 2 & $95.00 \pm 1.41$ & $145.00 \pm 0.00$ \\
\hline $\begin{array}{l}\text { Bình thường } \\
(\text { BMI: } 18.5-22.99)\end{array}$ & 40 & $96.58 \pm 8.13$ & $159.65 \pm 9.28$ \\
\hline $\begin{array}{l}\text { Thừa cân } \\
(\text { BMI: } 23-24.99)\end{array}$ & 22 & $101.59 \pm 8.97$ & $164.82 \pm 11.35$ \\
\hline $\begin{array}{l}\text { Béo phì } \\
(\text { BMI } \geq 25)\end{array}$ & 33 & $106.09 \pm 11.89$ & $174.45 \pm 15.32$ \\
\hline p & & 0.001 & 0.004 \\
\hline
\end{tabular}

Đánh giá mối liên quan giữa chỉ số $\mathrm{BMI}$ với với THA, trong nghiên cứu của Đào Thu Giang và cs nghiên cứu trên 132 BN điều trị tại BV Trung ương Quân đội 108 từ 2/2004-12/2005, tuổi từ 44-79. 
Chia 3 nhóm: nhóm $1(\mathrm{~N} 1)$ không thừa cân $(\mathrm{BMI}<23 \mathrm{~kg} / \mathrm{m} 2)$ gồm $30 \mathrm{BN}$; nhóm $2(\mathrm{~N} 2)$ thừa cân (BMI $=23$ đến 24,9kg/m2) gồm $33 \mathrm{BN}$, nhóm $3(\mathrm{~N} 3)$ béo phì $(\mathrm{BMI} \geq 25 \mathrm{~kg} / \mathrm{m} 2)$ gồm $69 \mathrm{BN}$. Kết quả cho thấy HATT và HATTr của $\mathrm{N} 2$ và $\mathrm{N} 3$ cao hơn và có ý nghĩa thống kê so với $\mathrm{N} 1$ với $\mathrm{p}<0.05$. Chỉ số BMI có hệ số tương quan thuận với huyết áp tâm thu và huyết áp tâm trương với $r=0,23$ và $r=0,34$ [6]. Trong nghiên cứu của chúng tôi, giá trị HATT và HATTr tăng dần theo chỉ số BMI, cao nhất ở nhóm béo phì có $\mathrm{BMI} \geq 25$ lần lượt là $174.45 \pm 15.32 \mathrm{mmHg}$ và $106.09 \pm 11.89 \mathrm{mmHg}$. Sự khác biệt có ý nghĩa thống kê với $\mathrm{p}<0.01$.

Bảng 7. Mối liên quan giữa THA với vòng bụng

\begin{tabular}{|l|c|c|c|}
\hline \multirow{2}{*}{\multicolumn{1}{c|}{$\begin{array}{c}\text { Chỉ số đánh giá } \\
\text { tương quan }\end{array}$}} & \multicolumn{2}{|c|}{ Vòng bụng } & \multirow{2}{*}{ PT tương quan } \\
\cline { 2 - 3 } & $\mathbf{r}$ & $\mathbf{p}$ & \\
\hline HATT & 0.56 & 0.000 & HATT $=1.654 \times$ VB +17.582 \\
\hline HATTr & 0.44 & 0.000 & HATTr $=0.977 \times$ VB +13.546 \\
\hline
\end{tabular}

Đánh giá mối liên quan giữa THA với vòng bụng: trong các điều tra dịch tễ học THA trước đây, số đo vòng bụng trung bình của dân số nói chung rơi vào khoảng $70-80 \mathrm{~cm}$ như trong nghiên cứu của Phạm Gia Khải và Nguyễn Lân Việt năm 2002 nghiên cứu trên 1324 đối tượng $\geq$ 25 tuổi tại miền đồng bằng tỉnh Thái Bình, kết quả cho thấy vòng bụng trung bình chung của nam giới là $70.65 \pm 6.58 \mathrm{~cm}$ và của nữ giới là $67.64 \pm 6.92 \mathrm{~cm}$, tính chung cho cả 2 giới là $68.94 \pm 6.96 \mathrm{~cm}$ [7]. Về mối liên quan giữa THA với vòng bụng, các nghiên cứu đều khẳng định giữa THA và vòng bụng có mối tương quan thuận vòng bụng càng cao thì giá trị HATT và $\mathrm{HATTr}$ càng tăng. Trong nghiên cứu của Đào Thu Giang, số đo vòng bụng có hệ số tương quan thuận với huyết áp tâm thu và huyết áp tâm trương với $\mathrm{r}=0,35$ và $\mathrm{r}=0,42$ [3]. Số đo vòng mông ít tương quan với huyết áp tâm thu và huyết áp tâm trương. Theo Phạm Gia Khải và Nguyễn Lân Việt, tỷ lệ Vòng bụng/vòng mông (WHR: Waist/Hip ratio) so với người bình thường $(\mathrm{WHR}<0.85)$ thì khi $\mathrm{WHR}$ $>0.85$ thì nguy cơ bị THA cao gấp 1.65 lần ở nam giới, 4.90 lần ở nữ giới và nguy cơ này cao nhất khi WHR từ $0.90-0.95$ (hơn 8 lần đối với nam và hơn
11 lần đối với nữ) [7].

Trong nghiên cứu này của chúng tôi, vòng bụng trung bình các đối tượng nghiên cứu là $88.67 \pm 5.66 \mathrm{~cm}$. Trong đó vòng bụng của đối tượng nữ cao hơn nam giới (lần lượt là $89.83 \pm$ $5.50 \mathrm{~cm}$ và $87.27 \pm 5.59 \mathrm{~cm}$ ), sự khác biệt có ý nghĩa thống kê với $\mathrm{p}<0.05$. Kết quả của chúng tôi khác với kết quả nghiên cứu của Phạm Gia Khải và Nguyễn Lân Việt là đối tượng nam có vòng bụng cao hơn nữ. Điều này có thể được giải thích là do tập quán sinh hoạt, vận động, ăn uống của người dân tộc có nhiều đặc điểm riêng khác với đối tượng người dân tộc Kinh. Người dân tộc thích ăn đồ nếp, đặc biệt là xôi gạo nếp, ăn nhiều đồ chiên nướng nhiều dầu mỡ, uống rượu bia những dịp lễ tết cả nam và nữ, đặc biệt là thói quen ăn mặn là đặc trung riêng của người dân tộc sống ở vùng cao. Do đó tỷ lệ THA ở phụ nữ của người dân tộc thường cao hơn so với các dân tộc khác. Kết quả này cũng phù hợp với nghiên cứu của Hoàng Thị Thúy Hà năm 2016 điều tra tại 30 xã, phường, thị trấn thuộc tỉnh Sơn La với tổng số đối tượng được điều tra là 1530 người trên 60 tuổi, kết quả cho thấy tỷ lệ tăng huyết áp của các 
đối tượng nghiên cứu là 50,2\%, trong đó nam giới $34,8 \%$ và nữ $65,2 \%$.

Đánh giá sự tương quan giữa HATT và HATTr với vòng bụng, chúng tôi thấy giữa HATT và HATTr với vòng bụng có mối tương quan thuận, mức độ vừa với $\mathrm{r}_{\mathrm{TT}}=0.56$ và $\mathrm{r}_{\mathrm{TTr}}=$ 0.44 (Bảng 3.17). Kết quả của chúng tôi phu hợp với các nghiên cứu trước đây.

\section{KẾT LUẬN}

Qua nghiên cứu 97 bệnh nhân người dân tộc thiểu số được chẩn đoán THA điều trị tại Khoa Nội chung - Bệnh viện Quân y 6 từ tháng 4/2019 đến 10/2019, chúng tôi rút ra một số kết luận sau:

- Nhận thức, thái độ của người dân tộc thiểu số về tăng huyết áp còn rất hạn chế so với vùng đồng bằng, thành phố. Số đối tượng chưa nghe về bệnh THA chiếm $19.59 \%$; BN có kiểm tra định kỳ HA 7.21\%, khi có triệu chứng 24.74\%, không kiểm tra 68.04\%; đối tượng biết về tai biến, biến chứng do THA nhưng không đầy đủ chiếm 26.81\%; đối tượng biết cách phòng tránh THA không đầy đủ 46.39\%, không biết 53.61\%.

- Mối liên quan giữ THA với tuổi không có ý nghĩa thống kê $\mathrm{p}>0.05$; HATB giới nữ cao hơn giới nam, $\mathrm{p}<0.05$; HA tăng tỷ lệ thuận với $\mathrm{BMI}, \mathrm{p}<0.01$; Vòng bụng của người dân tộc thiểu số có xu hướng cao hơn người dân tộc kinh; vòng bụng trung bình nữ cao hơn nam, $\mathrm{p}<0.05$, có mối tương quan thuận, mức độ vừa với $\mathrm{HA}\left(\mathrm{r}_{\mathrm{HATTr}}=0.44, \mathrm{r}_{\mathrm{HATT}}=0.56\right)$.

\section{TÀI LIỆ THAM KHẢO}

1. Phạm Tử Dương, Bệnh tăng huyết áp, NXB y học, 2005.

2. https://vncdc.gov.vn/cong-bo-ket-quadieu-tra-quoc-gia-yeu-to-nguy-co-benh-khonglay-nhiem-nam-2015-nd14421.html.

3. Nguyễn Lân Việt, Áp dụng một sổ giải pháp can thiệp thích hợp để phòng, chữa bệnh tăng huyết áp tại cộng đồng, Đề tài $\mathrm{NCKH}$ cấp bộ, 2007, tr 1-31.

4. Trần Văn Dũng, Nghiên cứu tình hình phòng chổng tăng huyết áp của người dân từ 25 tuổi trở lên tại huyện Vĩnh Châu tỉnh Sóc Trăng, Luận án chuyên khoa cấp II, 2009.

5. Phạm Thị Kim Lan, Tìm hiếu một số yếu tố nguy cơ của nguời tăng huyết áp tại nội thành Hà Nội, Luận văn tốt nghiệp bác sĩ chuyên khoa cấp II, 2002, tr 26-48.

6. Đào Thu Giang, Nguyễn Kim Thủy, Tìm hiểu mối liên quan giữa thừa cân, béo phì với tăng huyết áp nguyên phát, Tạp chí $\mathrm{Y}$ học thực hành, số 5 (542), 2006, tr 12-14.

7. Phạm Gia Khải, Nguyễn Lân Việt, Phạm Thái Sơn và cs, Tần suất tăng huyết áp và các yếu tố nguy cơ ở các tỉnh phía Bắc Việt Nam 2001 - 2002, Tạp chí Tim mạch học, số 33, 2003, $\operatorname{tr} 9-34$. 